\title{
Peningkatan Pendapatan Keluarga Melalui Usaha Kue Kering Desa Argosari Jabung
}

\author{
${ }^{1}$ Tita Boedi Astuti, ${ }^{2}$ Widanarni Poedjiastuti \\ 1,2 Sekolah Tinggi Ilmu Ekonomi (STIE) Malangkuçeçwara \\ 1email: tbast@stie-mce.ac.id \\ 2email: widanar@stie-mce.ac.id
}

\begin{abstract}
Partners in the Community Partnership Program (PKM) activities, namely Tuk'ah's mother pastry entrepreneurs who produce cookies on the basis of orders, except on holidays. The equipment used by Partners is very simple and many have been damaged, as well as a place to produce, therefore some equipment is needed in accordance with production capacity and some training both in managerial and product terms. Pastry entrepreneurs have high potential to be developed because pastries are one of the favorite cakes among all people and the marketing area is still around. This community service activity aims to increase production capacity and increase family income. The method applied in this partnership program is training, mentoring and monitoring so that partners continue to grow and be able to compete with similar businesses. The results of this community partnership program are procurement of tools to support the production process, improvement of production sites and training and assistance in making simple bookkeeping, marketing and entrepreneurship, training in variants of pastries. It is hoped that the PKM Program (Community Partnership Program) will be able to solve the problems faced by partners so that it will create a larger pastry business and increase family income.
\end{abstract}

\section{Keyward: microbusiness, pastries}

\section{PENDAHULUAN}

Saat ini pertumbuhan penduduk tidak sebanding dengan pertumbuhan ekonomi. Pada kondisi masyarakat saat ini sungguh sebuah dilema kehidupan yang tetap dijalani oleh setiap lapisan masyarakat. Lapangan pekerjaan yang sulit menjadi harapan bagi sebagian orang untuk mendapatkannya dan terkadang harus bersaing untuk mendapatkannya. Disini perlu sebuah kreatifitas atau ide untuk mencari peluang bahkan menciptakan lapangan pekerjaan baru (Jacobs, Posumah, \& Dengo, 2015) Sebuah keharusan bagi setiap individu maupun instansi untuk dapat menciptakan lapangan pekerjaan dalam rangka menciptakan sebuah tatanan kehidupan yang seimbang.

Masyarakat pada umumnya harus mau mencoba untuk berbuat dan berfikir kreatif dalam meciptakan peluang usaha untuk mencari sumber-sumber penghasilan yang sedikit banyak dapat membantu kehidupan keluarga maupun orang lain (Nasruddin, 2016) Hal ini tidak ketinggalan juga dengan masyarakat di desa Argosari kec. Jabung yang menjadi daerah mitra.

Selama ini masih banyak orang yang berfikiran bahwa kue kering adalah salah satu jenis sajian yang hanya ada pada saat hari raya dan acara -acara khusus lainnya. Oleh sebab itu tidak mengherankan jika melihat sebagian kalangan masyarakat 
menganggap bahwa usaha kue kering itu sebagai usaha yang musiman. Karena sifatnya musiman maka usaha kue kering tidak dapat dijadikan sebagai sumber mata pencaharian yang bisa diandalkan setiap tahunnya. Usaha kue kering memang paling tinggi menghasilkan pendapatan di saat hari raya besar. Tetapi sekecil apapun usaha itu, usaha kue kering dapat dijadikan lahan mata pencarian setiap hari sebagai peluang usaha ibu-ibu rumah tangga untuk menambah pendapatan keluarga.

Di desa Argosari, banyak ibu-ibu rumah tangga yang memproduksi kue kering. Karena proses pembuatan kue kering ini sangat mudah dan usaha kue kering mudah untuk dikembangkan, juga termasuk jenis makanan yang bisa diterima dan disukai diberbagai kalangan masyarakat. Bahan baku untuk membuat kue kering sangat mudah untuk diperoleh.. Kue kering ini juga mudah memasarkannya, bisa dijual diberbagai tempat. seperti dikantin-kantin kantor, di berbagai sekolah, ditokotoko.

Mitra dalam kegiatan Program Kemitraan Masyarakat (PKM) yaitu pengusaha kue kering ibu Tuk'ah. Peralatan yang digunakan juga masih sangat sederhana, pengerjaanya bersama keluarga yaitu dibantu anak-anaknya. Mitra ini memproduksi kue kering berdasarkan pesanan, kecuali pada hari raya mitra memproduksi secara masa, karena banyak yang memerlukan kue kering untuk hantaran maupun untuk suguhan. Selain rasanya yang enak dan harganya yang ekonomis banyak masyarakat lainnya yang berminat memesan kue ini.

Daerah pemasaran masih masih sangat terbatas yaitu di wilayah sekitar tempat tinggal, selain hasil produksi yang masih kalah bersaing. Juga peralatan yang digunakan oleh Mitra sangat sederhana dan sudah banyak yang rusak, oleh karena itu diperlukan beberapa peralatan yang sesuai dengan kapasitas produksi dan beberapa pelatihan baik dari segi manajerial maupun produk agar para produsen kue kering dapat meningkatkan penghasilan(Arianty, 2017)

\section{Gambaran mitra dari segi produksi adalah sebagai berikut :}

\section{Produk}

Ada berbagai macam produk yang dihasilkan mitra seperti kue kacang, semprit, kastengel, nastar, dan lain lain. Seperti tampak dibawah ini:

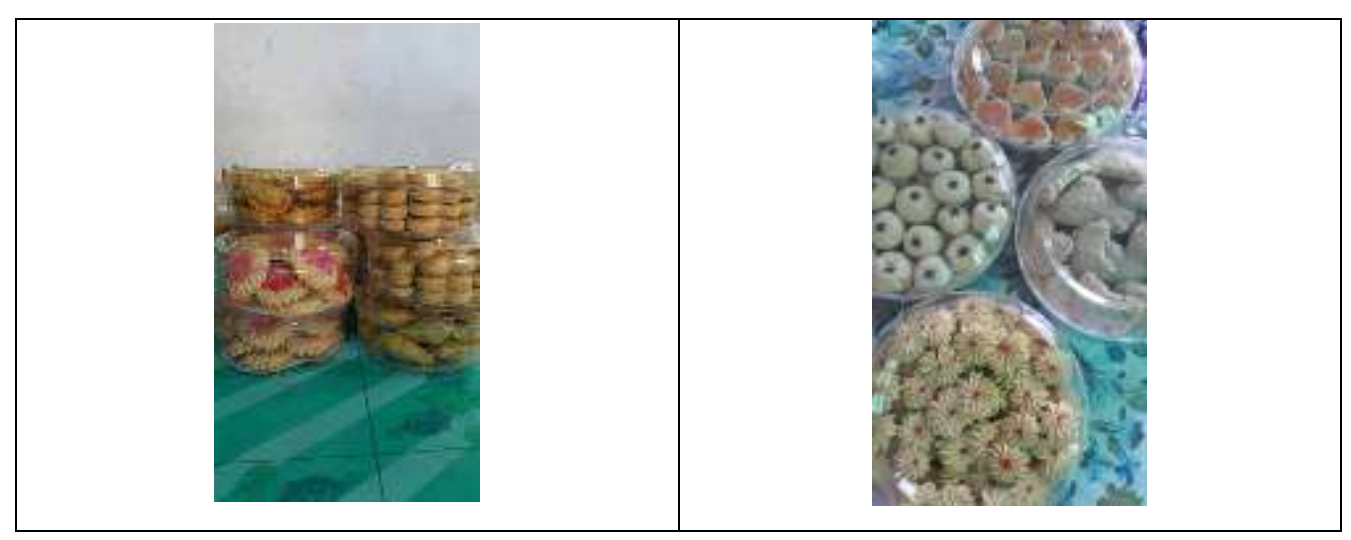




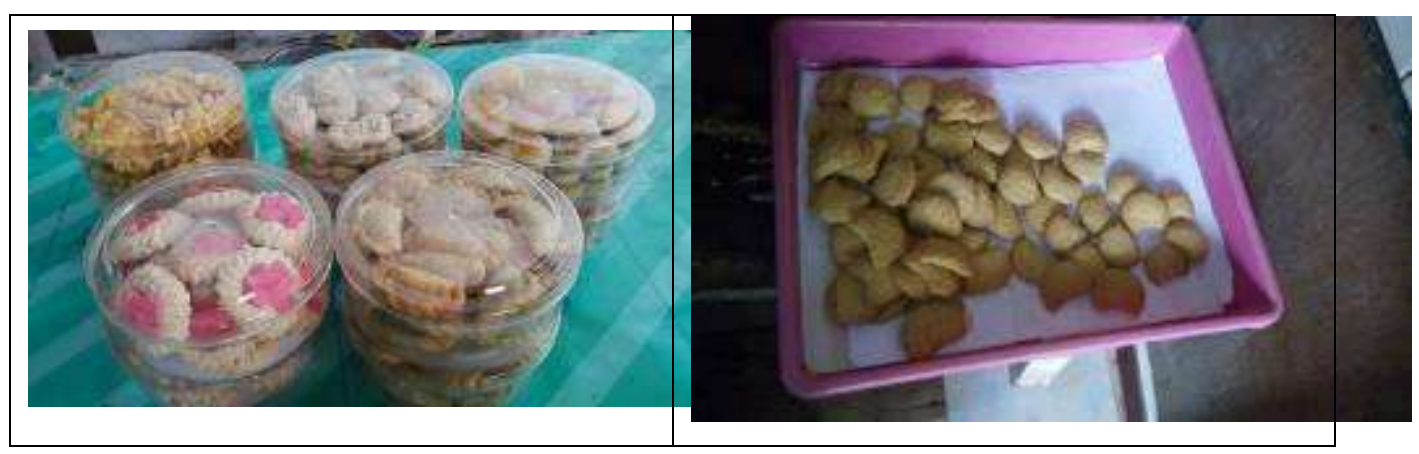

Gambar 1. Jenis kue yang dihasilkan

Berdasarkan hasil wawancara dengan mitra ada beberapa alasan yang mendasari mitra untuk mendirikan usaha kue kering :

a. Usaha ini sudah ditekuni dan dilakukan bersama keluarga.

b. Permintaan kue kering semakin meningkat disaat hari raya.

c. Cara penjualan Kue kering bisa dititipkan maupun pembeli datang langsung

d. Sebagai alternative lapangan kerja baru

\section{Bahan Baku}

Bahan-bahan untuk membuat kue kering mudah diperoleh ditoko-toko sekitar, sehingga tidak khawatir akan ketiadaan bahan -bahan untuk memproduksi kue kering.

\section{Peralatan yang dimiliki mitra}

Peralatan yang dimiliki mitra yang berstatus industri rumah tangga adalah :

1) Mixer atau alat pengaduk manua

2) Tempat untuk mengaduk adonan (baskom)

3) Sendok kue

4) Timbangan kue

5) Gelas ukur

6) Kantong semprot segitiga

7) Cetakan kue

8) Loyang

9) Oven manual

10) Kompor

11) Toples mika plastic

\section{Proses Produksi dan Kondisi Mitra}

Proses produksi yang dilakukan mitra masih sangat sederhana, masih menggunakan peralatan yang seadanya, juga untuk ovennya. Bisa dilihat digambar dibawah ini: 


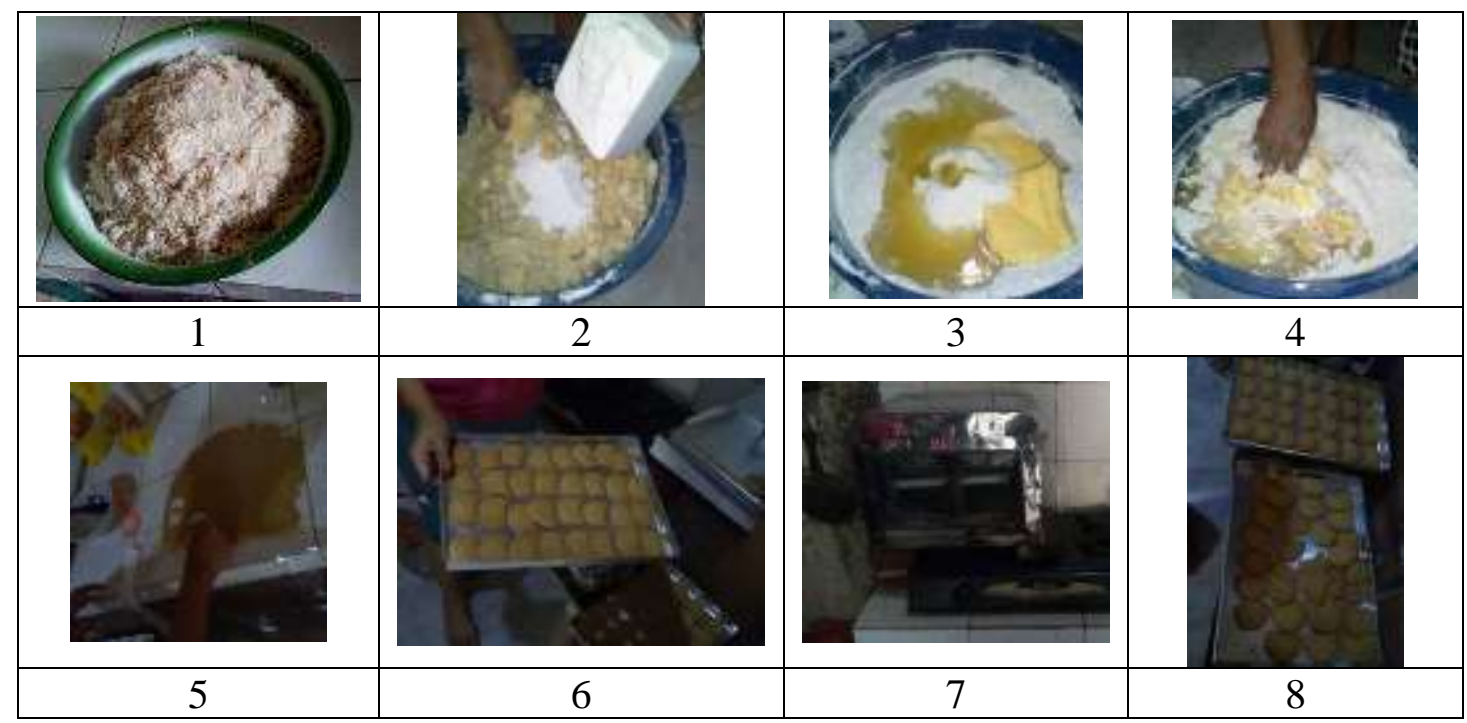

Gambar 2. Proses produksi

Dari gambaran proses produksi diatas, maka dapat digambarkan alur proses produksi sebagai berikut:

\begin{tabular}{|c|}
\hline Menyiapkan semua bahan \\
\hline 5 \\
\hline Dimixer \\
\hline كL \\
\hline Proses pencetakan \\
\hline Fك \\
\hline Di oven \\
\hline ط \\
\hline Didinginkan \\
\hline 5 \\
\hline Diatur- dimasukan toples mika \\
\hline
\end{tabular}

Gambar 3. Alur Proses Produksi

Tempat yang digunakan selama proses produksi perlu pembenahan karena perlu tempat yang lebih higienis. Kondisi ini dipengaruhi oleh kemampuan mitra yang masih kurang mampu untuk memperbaiki tempat produksinya.

\section{Gambaran mitra dari segi manajemen.}

\section{Manajemen dan Pemasaran}

Pola manajemen yang diterapkan dalam produksi kue kering ini, mitra masih menggunakan pola manajemen keluarga artinya bahwa usaha tersebut untuk memenuhi kebutuhan keluarga besarnya, belum menghitung kerugian atau keuntungan, selama hasil tersebut dapat memenuhi kebutuhan sehari-hari dan dapat untuk membeli bahan baku untuk membuat kue kering di hari berikutnya, dianggap sudah cukup. Tenaga kerja masih ada hubungan keluarga. Daerah pemasarannya Masyarakat sekitar, Teman dilingkungan kerja, keluarga, dan pesanan. 


\section{Permodalan dan Penghitungan Laba Rugi}

\section{- Permodalan}

Modal usaha pembuatan kue kering berasal dari modal sendiri artinya bahwa modal yang digunakan diperoleh dari uang pribadi atau dari tabungan. Jadi hasil penjualan hari ini akan digunakan untuk pembelian bahan untuk proses produksi hari berikutnya.

\section{- Penghitungan Laba Rugi}

Tabel 1. Rincian Biaya

\begin{tabular}{|l|c|c|}
\hline & Kuantitas & Harga (Rp) \\
\hline Terigu & $1 \mathrm{Kg}$ & 8.000 \\
\hline Kacang & $1 / 2 \mathrm{Kg}$ & 15.000 \\
\hline Gula & $1 / 2 \mathrm{Kg}$ & 6.500 \\
\hline Telor & $4 \mathrm{biji}$ & 5.000 \\
\hline Minyak & $1 \mathrm{Liter}$ & 12.500 \\
\hline Mentega & $1 / 2 \mathrm{Kg}$ & 10.000 \\
\hline Toples Plastik & 5 & 15.000 \\
\hline \multicolumn{2}{|c|}{ Total } & 72.000 \\
\hline
\end{tabular}

Pendapatan yang diperoleh Mitra adalah :

5 Toples plastic@ @p 25.000

$$
=\operatorname{Rp} .125 .000
$$

Total biaya

$=\mathrm{Rp} 72.000$.

Jadi total pendapatan sebesar

$$
=\operatorname{Rp} 53.000
$$

Dengan melihat perhitungan di atas menunjukkan bahwa usaha kue kering ini masih layak untuk terus dikembangkan oleh mitra, walaupun belum memperhitungkan tenaga kerja dan bahan bakar. Hal ini dikarenakan:

a. Merupakan sumber pendapatan keluarga sehingga semakin berkembangnya usaha ini diharapkan akan meningkatkan pendapatan.

b. Permintaan kue kering terus mengalami peningkatan disaat hari raya

c. Pembuatannya mudah

d. Perolehan bahan baku mudah.

e. Terciptanya lapangan kerja baru

f. Usaha sampingan keluarga.

\section{PERMASALAHAN}

Berdasarkan analisis situasi diatas dan wawancara dengan mitra ada 2 masalah yang berkaitan dalam pengembangan usaha, yaitu :

1. Dilihat dari segi produksi :

a. Permasalahan mitra, oven dan peralatan untuk proses produksi masih sangat sederhana, secara manual. Sehingga untuk proses produksi kurang memadahi.

b. Tempat produksi mitra perlu pembenahan. Didalam proses pembuatannya kue kering keadaan atau tempat produksi haruslah bersih dan higenis. Agar pembuatan kue tidak terhambat dengan keadaan tempat. Selain itu tempat juga menjadi cerminan dalam pembuatan kue kering, karena jika tempat pembuatan kue tidak bersih otomatis kue yang dibuat terkena kotoran dan mudah terjangkit penyakit. Semua ini akan dapat mengurangi rasa dari kue tersebut

2. Dilihat dari segi manajemen :

a. Belum pernah melakukan pembukuan, sehingga tidak pernah ada catatan laba maupun ruginya. 
b. Pengetahuan mitra mengenai manajemen pemasaran sangat terbatas, sehingga perlu ditingkatkan untuk menghadapi persaingan usaha.

c. Varian kue kering sangat terbatas

\section{Kendala lain yang muncul:}

1. Munculnya usaha yang sama pasca usaha ini.

2. Modal yang selalu berubah pada waktu-waktu tertentu akibat kebijakan ekonomi pemerintah, menyebabkan harga berubah.

3. Perubahan selera konsumen.

4. Pelanggan yang tidak tetap, selalu berubah

\section{Solusi terhadap permasalahan mitra :}

Berdasarkan analisis situasi diatas dan berdasarkan wawancara dengan mitra terhadap permasalahan-permasalahan prioritas maka solusi penyelesaiannya adalah sebagai berikut :

\begin{tabular}{|c|c|c|}
\hline Aspek -aspek & Permasalahan & Solusi \\
\hline 1. Produksi & $\begin{array}{ll}\text { a. } & \text { Oven sangat sederhana } \\
\text { (kecil) } \\
\text { b. Mixer dan pengaduk } \\
\text { adonan manual } \\
\text { c. Tempat produksi kurang } \\
\text { bersih } \\
\text { d. Peralatan untuk } \\
\text { mmembantu proses } \\
\text { produksi }\end{array}$ & $\begin{array}{l}\text { a. Pengadaan oven yang } \\
\text { lebih besar berikut } \\
\text { loyangnya } \\
\text { b. Pengadaan Mixer yang } \\
\text { lebih modern } \\
\text { c. Perbenahan tempat } \\
\text { produksi } \\
\text { d. Pengadaan peralatan } \\
\text { untuk membantu proses } \\
\text { produksi }\end{array}$ \\
\hline $\begin{array}{l}2 . \\
\text { Manajemen }\end{array}$ & $\begin{array}{l}\text { a. Pengetahuan pembukuan } \\
\text { rendah } \\
\text { b. Pemahaman manajemen } \\
\text { pemasaran rendah } \\
\text { c. Pengetahuan pengelolaan } \\
\text { usaha rendah } \\
\text { d. Belum ada inovasi produk } \\
\text { kue kering (macam kue } \\
\text { tetap) }\end{array}$ & $\begin{array}{l}\text { a. Pelatihan pembukuan } \\
\text { sederhana } \\
\text { b. Pelatihan manajemen } \\
\text { pemasaran dan wirausaha } \\
\text { c. Peningkatan pengelolaan } \\
\text { keuangan. } \\
\text { d. Pelatihan pengembangan } \\
\text { olahan kue kering }\end{array}$ \\
\hline
\end{tabular}

\section{METODE}

Dalam rangka mengatasi permasalahan yang dihadapi mitra adalah sebagai berikut :

1. Memotivasi mitra untuk terus mengembangkan usahanya agar kedepan akan menjadi lebih besar dan mampu untuk menciptakan lapangan kerja baru khususnya bagi masyarakat sekitar desa setempat.

2. Memberikan pelatihan kepada mitra cara pembuatan kue kering dan aneka varian agar bisa bersaing.

3. Memberikan pelatihan kepada mitra mengenai manajemen pemasaran dan kewirausahaan serta pelatihan cara pembukuan sederhana agar bisa mengetahui mengenai kondisi keuangan mitra yang diperoleh dari hasil usaha pembuatan kue kering. 


\section{HASIL DAN PEMBAHASAN}

\section{Prosedur kerja :}

Prosedur Kerja pelaksanaan PKM pengusaha kue kering adalah sebagai berikut :

\begin{tabular}{|c|}
\hline Pendekatan kepada kedua Mitra \\
\hline Melakukan wawancara ke mitra untuk mengetahui permasalahan yang dihadapi \\
\hline Perancangan peralatan yang diperlukan \\
\hline Penyerahan peralatan \\
\hline Pembenahan tempat produksi \\
\hline Pelatihan dan pendampingan manajemen pemasaran dan pembukuan sederhana \\
\hline Pelatihan dan pendampingan pembuatan kue kering dan aneka variannya \\
\hline Monitoring \\
\hline
\end{tabular}

Selama pelaksanaan program hibah pengabdian dalam Program Kemitraan Masyarakat ini hasil dan luaran yang telah dicapai adalah :

\section{Perbaikan Tempat Produksi}

Perbaikan tempat produksi dilakukan agar tempat produksi lebih rapid an bersih sehingga dalam mengerjakan lebih mudah karena tempat sudah disesuaikan dengan alur proses produksi dan diharapkan hasil produknya lebih higienis.
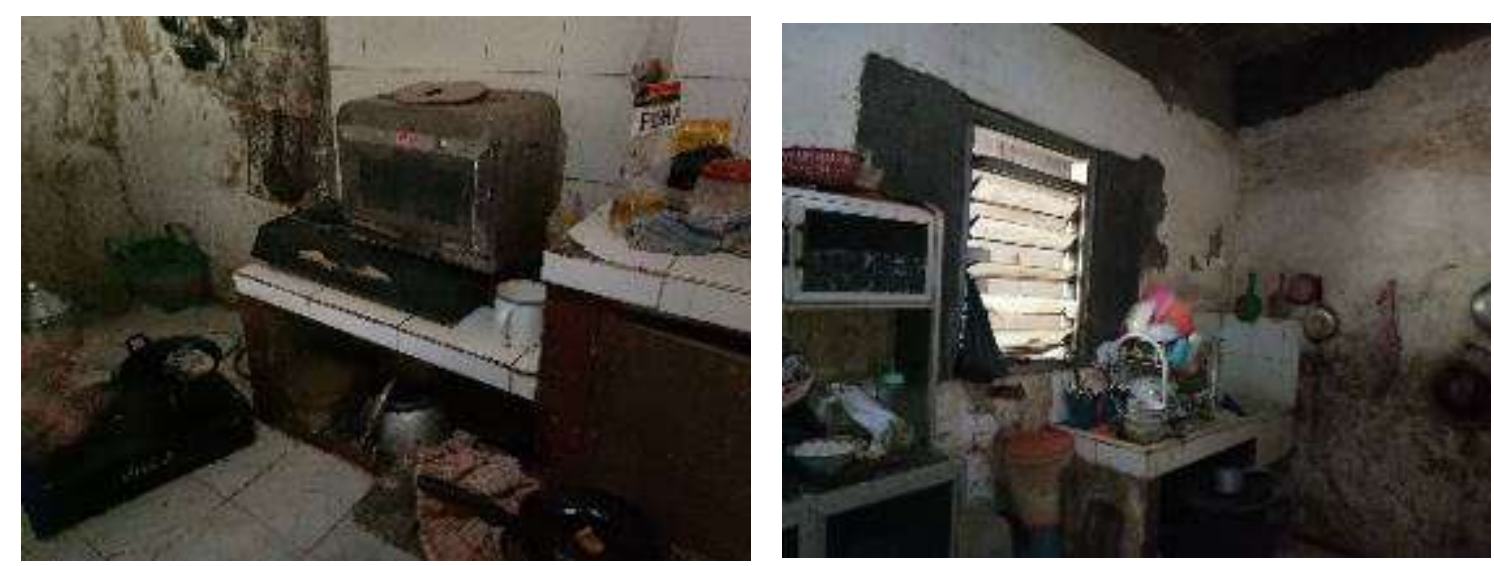

Gambar 4. Kondisi Mitra sebelum PKM 

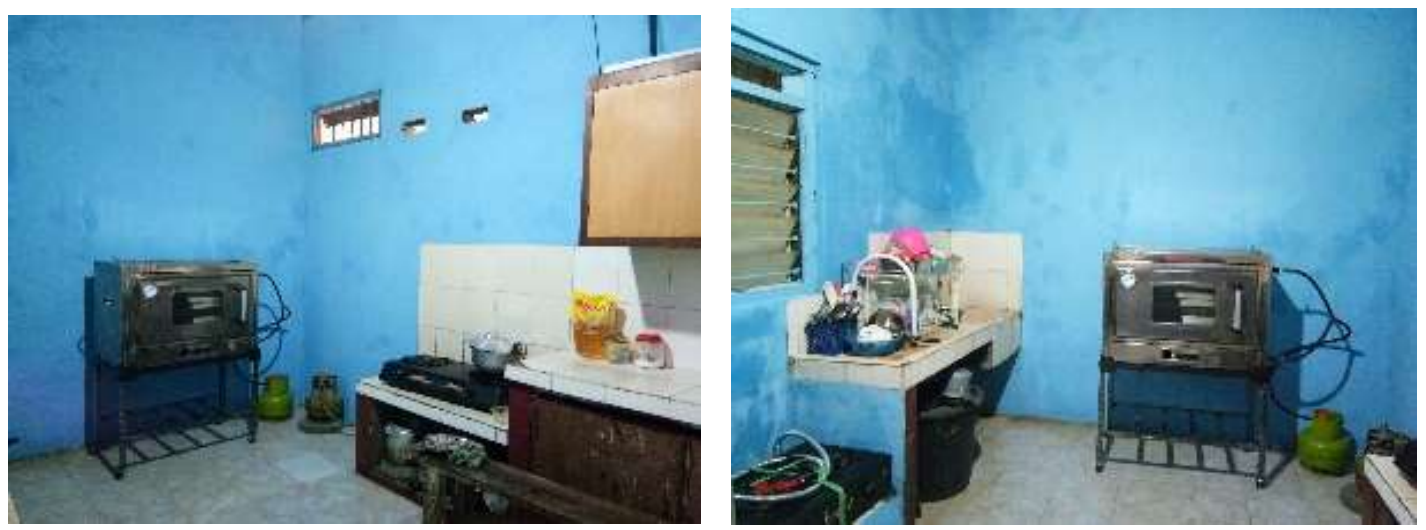

Gambar 5. Kondisi Mitra setelah PKM

\section{Pemberian Alat}

Untuk menunjang proses produksi, maka mitra PKM memerlukan peralatan yang memadai. Karena permintaan akan produk kue kering semakin meningkat dan daerah pemasaran juga mulai berkembang tidak hanya disekitar tempat tinggal, juga sudah mulai kedaerah malang raya. Juga Mitra sudah bisa menerima pesanan kue selain kue kering yang menggunakan oven, antara lain wingko yang biasanya diovenkan ketempat lain dengan biaya Rp 20.000,00 per sekali oven per buah.
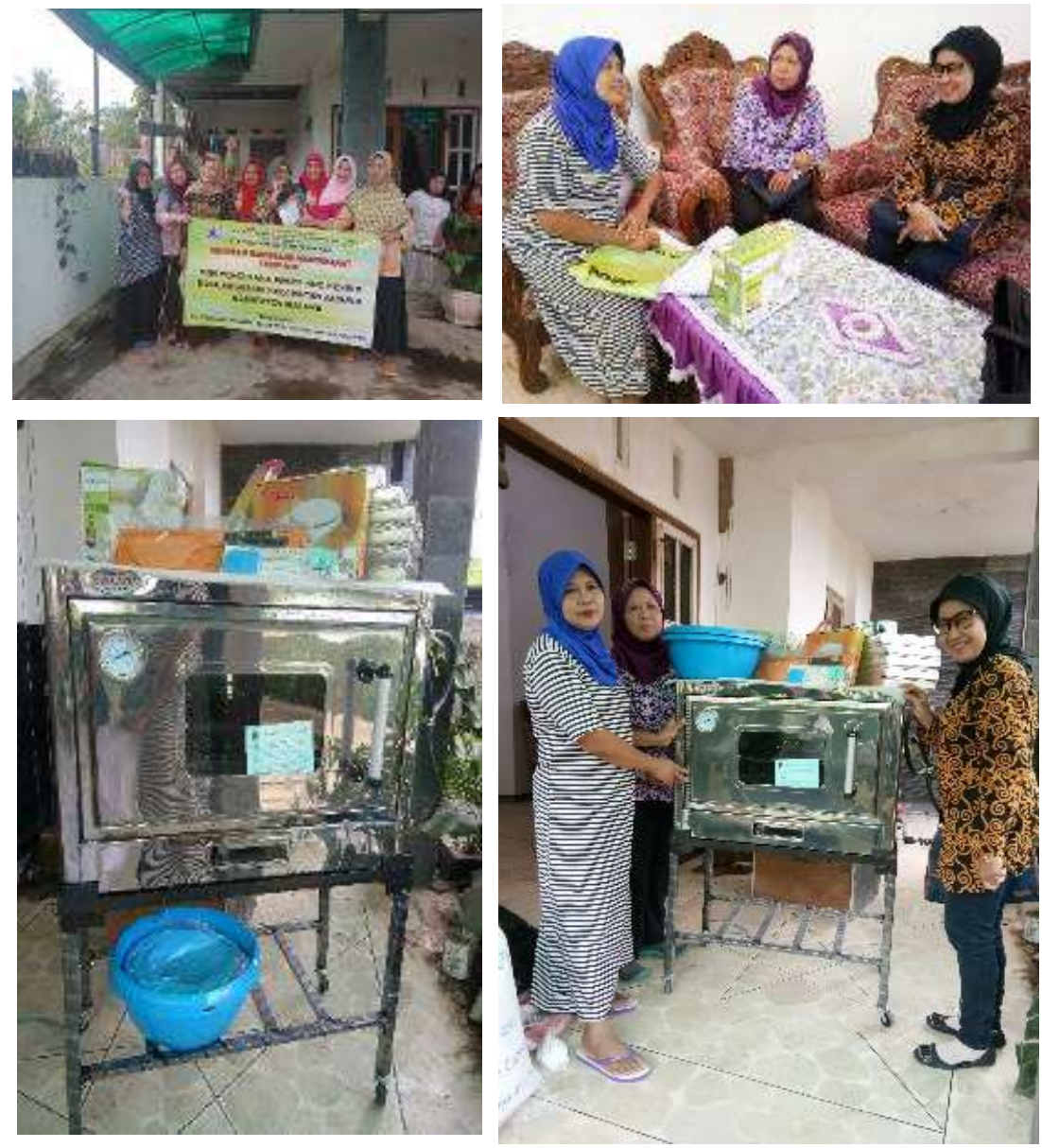


\section{Pelatihan dan pendampingan}

\section{Gambar 6. Peralatan Yang Diberikan}

Pelatihan dan pendampingan yang telah dilakukan yaitu pelatihan dan pendampingan pembuatan laporan keuangan sederhana, kewirausahaan, manajemen pemasaran dan pembukuan sederhana, pembuatan kue kering dan aneka variannya.
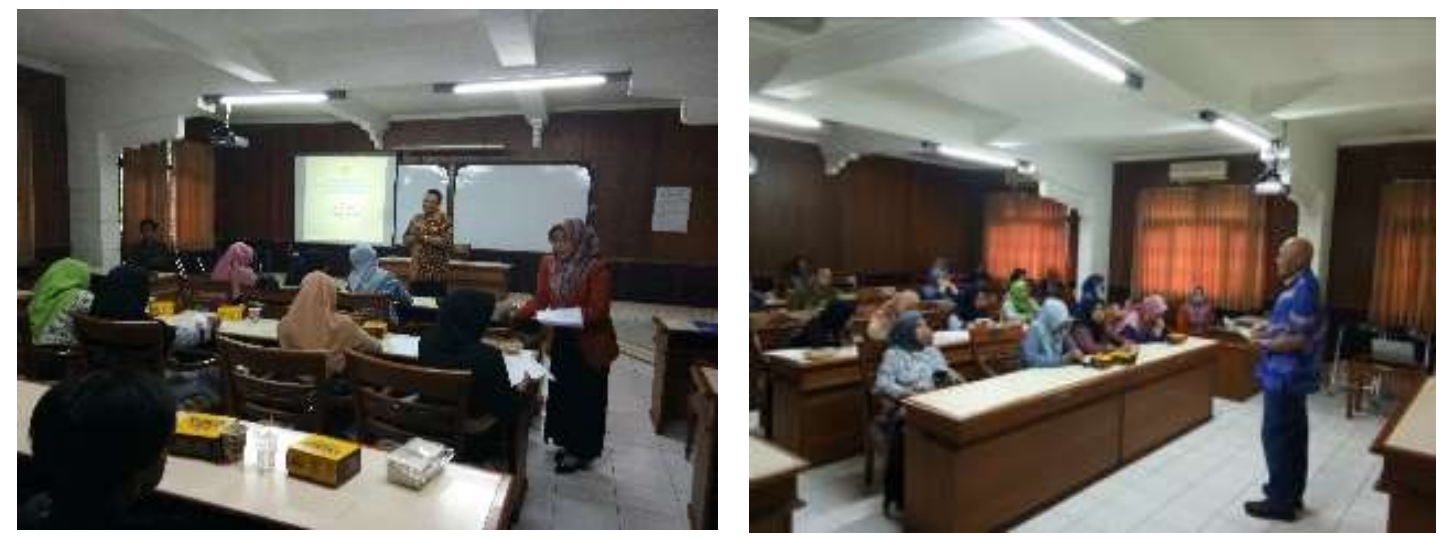

Gambar 7. Pelatihan

\section{Pengurusan PIRT dan pemberian label produk dengan nama Engela Cookis}

Pemberian PIRT dan label produk bertujuan untuk melegalkan merk dan melindungi hak pencipta. Dengan demikian produsen bisa memasarkan produknya dengan leluasa.

\section{Monitoring}

Monitoring perlu dilakukan agar program ini tetap terlaksana dengan baik sehingga dapat bermanfaat untuk mitra. Kegiatan monitoring dilakukan sebulan sekali, untuk melihat aktivitas dan perkembangan mitra, sehingga dari hasil tersebut bisa digunakan sebagai bahan evaluasi.

\section{KESIMPULAN}

Program Kemitraan Masyarakat tentang Peningkatan Pendapatan Keluarga Melalui Usaha Kue Kering di Desa Argosari Jabung telah berhasil meningkatkan kualitas dan kuantitas produknya dan memberikan bekal ke mitra untuk mengembangkan usahanya dengan beraneka ragam kue kering serta kue kue selain kue kering yang menggunakan oven.

Hasil yang telah dicapai dalam program ini adalah pengadaan peralatan penunjang proses produksi. Selain itu juga dilakukan perbaikan tempat produksi juga pelatihan dan pendampingan untuk peningkatan sumberdaya manusianya dan varian kue kering. Diharapkan dengan adanya Program Kemitraan Masyarakat yang telah dilakukan, usaha mitra semakin berkembang dan bisa bersaing dengan usaha yang sejenis.sehingga diharapkan pendapatan keluarga semakin meningkat. Pengurusan PIRT dan pelabelan juga Publikasi di media online maupun media masa juga telah dilaksanakan guna memberikan motivasi mitra untuk semakin berkembang. Dengan adanya PIRT diharapkan tingkat higienis produk semakin meningkat sehingga kepercayaan konsumen terhadap produk kue kering merk Engela Cookies juga semakin meningkat. 


\section{DAFTAR PUSTAKA}

Arianty, N. (2017). Analisis Usaha Industri Rumah Tangga Dalam Meningkatkan. Prosiding Seminar Hilirisasi Penelitian Untuk Kesejahteraan Masyarakat Lembaga Penelitian Universitas Negeri Medan, (September 2017).

Jacobs, F. P., Posumah, J. H., \& Dengo, S. (2015). Pengaruh Pemberdayaan Usaha Kecil Terhadap Peningkatan Pendapatan Usaha di Kecamatan Singkil Kota Manado. Jurnal Administrasi Publik UNSRAT, 3(031), 1-13.

Nasruddin, M. (2016). Analisis Peran UKM CV.Citra Sari Terhadap Peningktan Ekonomi Kelurga Karyawan). 